\title{
An Open-Label Study of the Long-Term Safety of Pirfenidone in Patients with Idiopathic Pulmonary Fibrosis (RECAP)
}

\author{
Ulrich Costabel $^{a}$ Carlo Albera $^{b}$ Lisa H. Lancaster ${ }^{c}$ Chin-Yu Lin ${ }^{d}$ \\ Philip Hormel $^{d}$ Henry N. Hulter ${ }^{d}$ Paul W. Noble ${ }^{e}$

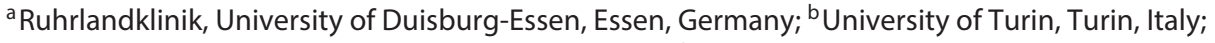 \\ 'Vanderbilt University Medical Center, Nashville, TN, d Genentech, Inc., South San Francisco, CA, and \\ e Cedars-Sinai Medical Center, Los Angeles, CA, USA
}

\section{For editorial comment see p. 405}

\section{Keywords}

Idiopathic pulmonary fibrosis · Pirfenidone · Long-term safety

\begin{abstract}
Background: RECAP (NCT00662038) was an open-label extension study in patients with idiopathic pulmonary fibrosis (IPF) who completed either the Assessment of Pirfenidone to Confirm Efficacy and Safety in Idiopathic Pulmonary Fibrosis (ASCEND) 016 phase 3 trial or the Clinical Studies Assessing Pirfenidone in Idiopathic Pulmonary Fibrosis: Research of Efficacy and Safety Outcomes (CAPACITY) 004/006 phase 3 trials. Objective: To obtain long-term safety data for pirfenidone in patients with IPF in RECAP. Methods: Of the 1,334 patients who participated in the phase 3 trials, 1,058 entered RECAP. The final analysis from enrollment (September 2008) to June 2015 is presented. Results: Mean (SD) and median (range) pirfenidone exposures in RECAP were 122 (98) weeks and 88 (>0 to 349 ) weeks, respectively, with a mean daily dose of 2,091.1 mg. Cumulative total exposure was 2,482 patient exposure years (PEY). The treatment-emergent adverse event (TEAE) rate was 701.9 per 100 PEY. The serious TEAE rate was 53.5 per $100 \mathrm{PEY}$, with the most common serious TEAE being IPF (11.1 per 100 PEY). Of the 231 deaths (9.3 per
\end{abstract}

\section{KARGER}

E-Mail karger@karger.com www.karger.com/res
C 2017 The Author(s)

Published by S. Karger AG, Basel

This article is licensed under the Creative Commons AttributionNonCommercial-NoDerivatives 4.0 International License (CC BYNC-ND) (http://www.karger.com/Services/OpenAccessLicense) Usage and distribution for commercial purposes as well as any distribution of modified material requires written permission.
100 PEY), the most common cause was IPF (5.4 per 100 PEY). The treatment discontinuation rate due to a TEAE was 17.9 per 100 PEY; discontinuations were due to IPF (7.2 per 100 $\mathrm{PEY})$, pneumonia, respiratory failure, acute respiratory failure, rash (0.5 per 100 PEY each), and nausea (0.4 per $100 \mathrm{PEY}$ ). For patients from CAPACITY 004/006 who entered RECAP, the mean change in percent predicted forced vital capacity from RECAP baseline at 180 weeks was $-9.6 \%$. Median ontreatment survival from the first pirfenidone dose in RECAP was 77.2 months. Conclusions: RECAP provides long-term follow-up and safety data for pirfenidone that were consistent with the known profile, with no new safety signals observed.

(c) 2017 The Author(s) Published by S. Karger AG, Basel

\section{Introduction}

Idiopathic pulmonary fibrosis (IPF) is a serious, devastating, progressive, and often fatal fibrosing lung disease. Pirfenidone is an oral antifibrotic agent with antiinflammatory properties that was approved for the treatment of IPF in the European Union in 2011 and in the United States in 2014. In the 2015 update of the American Thoracic Society, European Respiratory Society, Japanese

Ulrich Costabel, MD

Interstitielle und seltene Lungenkrankheiten, Ruhrlandklinik Westdeutsches Lungenzentrum am Universitätsklinikum Essen gGmbH Tüschener Weg 40, DE-45239 Essen (Germany)

E-Mail ulrich.costabel@ ruhrlandklinik.uk-essen.de 
Respiratory Society, and Latin American Thoracic Association treatment guidelines for IPF, pirfenidone is conditionally recommended for the treatment of IPF [1].

In clinical trials, pirfenidone has slowed disease progression and decreased mortality compared with placebo, and observations of attenuated decline in lung function (forced vital capacity, FVC) from real-world data are consistent with findings from clinical trials [2-8]. Pirfenidone slowed disease progression as measured by changes in FVC $[9,10]$ and reduced the risk of death from any cause by $48 \%$ at 1 year $[3,11]$. In addition, a treatment benefit for pirfenidone was observed for other outcomes, including 6-min walking distance and progression-free survival $[2,11]$.

Pirfenidone has a favorable benefit-risk profile, with well-characterized long-term safety and tolerability data as well as manageable side effects $[12,13]$. Gastrointestinal- and skin-related events, the most commonly reported side effects from pirfenidone, are often manageable with appropriate mitigation strategies and education [14, 15].

RECAP was an open-label extension study evaluating the long-term safety of pirfenidone in patients with IPF who completed the Clinical Studies Assessing Pirfenidone in Idiopathic Pulmonary Fibrosis: Research of Efficacy and Safety Outcomes (CAPACITY) 006 (PIPF006; NCT00287729), CAPACITY 004 (PIPF-004; NCT00287716), or the Assessment of Pirfenidone to Confirm Efficacy and Safety in Idiopathic Pulmonary Fibrosis (ASCEND; PIPF-016; NCT01366209) trial [16]. Here we present the primary analysis of the RECAP study.

\section{Methods}

\section{Patients}

To be eligible for RECAP, patients had to have completed the final visit and not have permanently discontinued pirfenidone in a previous, qualifying phase 3 clinical trial (CAPACITY 004/006 or ASCEND 016). Patients were to be enrolled in RECAP within 10 days of completing the final visit in their qualifying trial. Enrollment of CAPACITY 004/006 patients into RECAP was initiated nearly 4 years before the patients from ASCEND first entered RECAP.

\section{Study Design}

RECAP (PIPF-012) was an open-label, multicenter, singlearm, rollover study for patients with IPF who completed CAPACITY 004/006 or ASCEND. The primary objective was to obtain additional safety data for pirfenidone $2,403 \mathrm{mg} /$ day. Patients entering this study from any of the parent studies transitioned from one of three treatment arms: pirfenidone 1,197 mg/day (CAPACITY 004 only), pirfenidone 2,403 mg/day, or placebo. All patients
Table 1. Patient demographics and baseline characteristics $(n=$ 1,058)

Age, years

$68.5(7.47)$

Age $\geq 65$ years

$745(70.4 \%)$

Male

$790(74.7 \%)$

White

$1,007(95.2 \%)$

Not Hispanic or Latino ethnicity

$947(89.5 \%)$

Male weight, $\mathrm{kg}$

Female weight, kg

$88.3(15.7)$

$73.6(14.6)$

Years since IPF diagnosis

$<2$

2 to $<4$

$309(29.2 \%)$

$572(54.1 \%)$

$\geq 4$

$176(16.7 \%)$

For CAPACITY 004/006 patients only

FVC, \% predicted

$\mathrm{DL}_{\mathrm{CO}}, \%$ predicted $^{1}$

$70.9(16.68)$

$41.2(12.41)$

Values are presented as mean (SD) or $n(\%)$. Note that the collection of baseline assessments varied by parent study, but in general, baseline was defined as the last assessment before first dose. CAPACITY, Clinical Studies Assessing Pirfenidone in Idiopathic Pulmonary Fibrosis: Research of Efficacy and Safety Outcomes; $\mathrm{DL}_{\mathrm{CO}}$, diffusing capacity for carbon monoxide; FVC, forced vital capacity; IPF, idiopathic pulmonary fibrosis. ${ }^{1}$ Corrected for hematocrit.

were treated as if they had been receiving placebo during the phase 3 trials due to patients entering RECAP before the unblinding in the parent study.

Patients received pirfenidone $2,403 \mathrm{mg} /$ day in equally divided doses three times per day with food [17]. The pirfenidone dose was titrated from $801 \mathrm{mg} /$ day over the first 15 days in RECAP to the maintenance dose of $2,403 \mathrm{mg} /$ day or as high as was tolerated $(\leq 2,403 \mathrm{mg} /$ day $)$, depending on investigator judgment. The duration of treatment for each patient continued until pirfenidone became commercially or otherwise available. Written informed consent was required from all patients, and the study protocol was approved by the institutional review board or ethics committee at each center.

\section{Study Assessments}

Patients were assessed via telephone at week 1 . Physical examination and clinical laboratory assessments were performed at baseline and at weeks 2, 4, 6, and 12 and at 12-week intervals thereafter. A directed history, including a review of adverse events (AEs), serious AEs, concomitant medications, and treatment adherence, was recorded at each visit. FVC, forced expiratory volume in $1 \mathrm{~s}$, and diffusing capacity for carbon monoxide were measured at baseline and at week 12, then every 24 weeks. Week 8, 16, and 20 visits were added for clinical lab assessments of liver chemistries when the patients from ASCEND entered the study.

The analysis population consisted of all patients who were enrolled and received $\geq 1$ dose of pirfenidone. The primary analysis was based on data collected as of June 30,2015, with 5 of the 1,058 patients still ongoing. Assessments at each time point and their changes from baseline were summarized with descriptive statistics from all study visits, using all available data. Kaplan- 


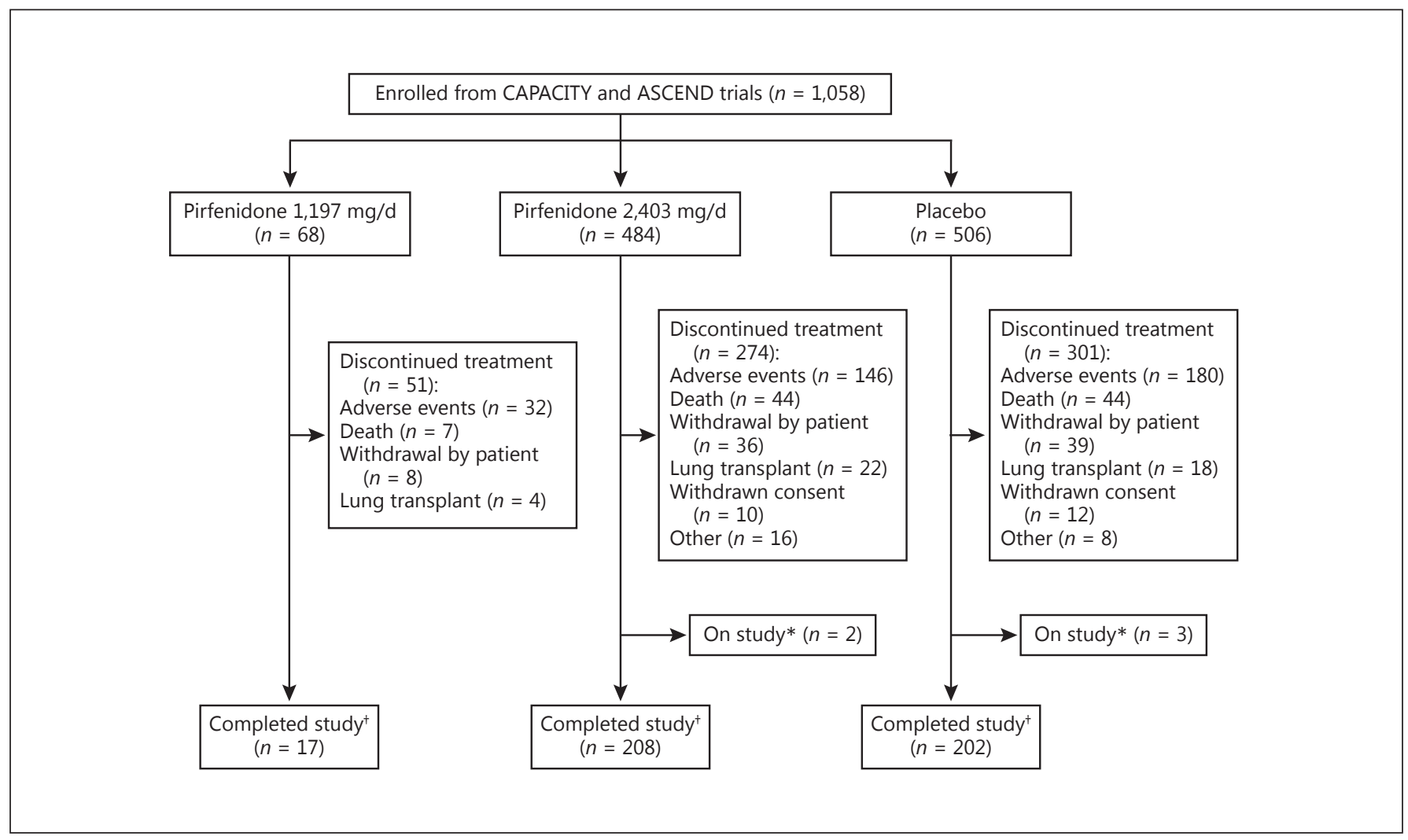

Fig. 1. Patient disposition in RECAP. Patients who had received prior pirfenidone $1,197 \mathrm{mg}$ /day, pirfenidone $2,403 \mathrm{mg} /$ day, or placebo were enrolled into RECAP. ASCEND, Assessment of Pirfenidone to Confirm Efficacy and Safety in Idiopathic Pulmonary Fibrosis; CAPACITY, Clinical Studies Assessing Pirfenidone in Idiopathic Pulmonary Fibrosis: Research of Efficacy and Safety

Meier estimates were used to summarize time to early discontinuation of pirfenidone. Efficacy data were collected on rollover patients from CAPACITY 004/006 through May 2012, when patients from ASCEND entered the study. No efficacy data were collected after that time because these data would not be comparable due to differences in the study design between the ASCEND and CAPACITY 004/006 trials. Kaplan-Meier estimates were used to summarize survival time, as measured by time from the first dose of pirfenidone in RECAP to death (all-cause mortality). The annualized rate of decline in FVC volume was estimated using a random coefficient regression model (with random slopes and intercepts) that included sex, age, and height as covariates. The decrease in FVC was assumed to be linear within each patient. The intercepts and slopes were assumed to be normally distributed with an unstructured covariance matrix. The within-patient error was assumed to be independent and normally distributed with mean zero and a common variance. All observed FVC volumes from baseline were included in the model. Missing data were imputed implicitly by the model assuming missing at random.

The primary survival analysis was a treatment-emergent analysis, in which all deaths occurring within 28 days after the last dose
Outcomes. * Patients were considered to have been on study if they were still in the study at the time the study was terminated. ${ }^{\dagger} \mathrm{Pa}$ tients were considered to have completed the study if they were active at the time their study site was closed due to availability of commercial pirfenidone or a posttrial access program.

were included as events. Deaths occurring after the lung transplantation date (if applicable) were excluded. Patients without events were censored at their lung transplantation date (if applicable), their last known alive date, or their last dose date plus 28 days, whichever was earlier.

Safety data collected throughout the study included treatment-emergent adverse events (TEAEs) and laboratory results. TEAEs were events occurring from the first dose in RECAP through 28 days after the last dose in RECAP. A dose interruption was defined as a dosing gap of $\geq 1$ day, excluding the initial dose escalation period. A drug holiday was defined as an interruption of $\geq 14$ days when the patient was not permanently discontinued from pirfenidone. Adverse drug reactions (ADRs) were AEs judged by the investigator as possibly or probably related to pirfenidone. AEs were summarized using patient incidence (defined as the number of patients with an event divided by total number of patients) and adjusted event rate per 100 patient exposure years (PEY) (defined as the number of events divided by the total PEY times 100).

All authors participated in the design, conduct, and analysis of the study. The authors had full access to data, and no limits were placed on reporting of the results by the study sponsor. 


\section{Results}

Baseline Characteristics, Patient Disposition, and Pirfenidone Exposure

From the CAPACITY 004/006 and ASCEND trials, 1,089 of 1,334 patients (81.6\%) with IPF completed the study treatment. Between September 2008 and January $2014,1,058$ of the 1,334 patients $(79.3 \%)$ entered into RECAP (online suppl. Table 1; for all online suppl. material, see www.karger.com/doi/10.1159/000479976).

Patients in RECAP were mostly white $(95.2 \%)$ and male $(74.7 \%)$ and had an IPF disease duration between 2 and 4 years (54.1\%; Table 1). For patients from the CAPACITY 004/006 trials at the start of RECAP, the baseline mean (SD) values for percent predicted FVC and percent predicted diffusing capacity for carbon monoxide were $70.9 \%(16.68 \%)$ and $41.2 \%(12.41 \%)$, respectively.

Of the 1,058 patients who entered RECAP, 427 patients $(40.4 \%)$ had completed the study, 626 patients (59.2\%) had discontinued it, and 5 patients in Mexico were still ongoing at the time of this analysis (Fig. 1; June 30, 2015). The 5 Mexican patients were all transferred to an alternative source of pirfenidone and discontinued from the study in February 2016. The median (95\% CI) time to study discontinuation was 150 (132-166) weeks (online suppl. Fig. 1A).

The mean (SD) and median (range) of pirfenidone exposure in RECAP was 122 (98) weeks and 88 ( $>0$ to 349) weeks, respectively, with a mean (SD) dose of 2,091.1 $(507.5) \mathrm{mg} /$ day. The majority of patients $(68.5 \%)$ received a mean daily dose of pirfenidone ranging from 2,200 to $2,403 \mathrm{mg} /$ day. The cumulative total exposure to pirfenidone was 2,482 PEY. Overall, 557 patients (52.6\%) had a dose interruption, and 202 patients (19.1\%) had $\geq 3$ dose interruptions. The median (range) duration of dose interruptions was $13(1-320)$ days.

\section{Safety}

The majority of patients (98.0\%) reported $\geq 1$ TEAE. The most frequent TEAEs based on incidence were IPF (33.6\%), cough (31.3\%), and dyspnea (30.9\%) (Table 2). When adjusted for exposure, the most frequent TEAEs were IPF (22.0 per 100 PEY), upper respiratory infection (21.1 per $100 \mathrm{PEY}$ ), and bronchitis (19.5 per $100 \mathrm{PEY}$ ). TEAEs resulting in pirfenidone withdrawal occurred in 444 patients (42.0\%; 17.9 per $100 \mathrm{PEY}$; Table 3) and included 95 patients who died. The most frequent TEAE leading to pirfenidone withdrawal was IPF (16.8\%; 7.2 per $100 \mathrm{PEY})$. However, of the patients who discontinued the study due to an $\mathrm{AE}(n=358), 243$ (67.9\%) discontinued
Table 2. Summary of TEAEs $(n=1,058)$

\begin{tabular}{|c|c|c|c|}
\hline \multirow[t]{2}{*}{ TEAEs } & \multirow[t]{2}{*}{$n(\%)$} & \multicolumn{2}{|c|}{ Adjusted rate ${ }^{1}$} \\
\hline & & $\begin{array}{l}\text { events, } \\
n\end{array}$ & $\begin{array}{l}\text { rate per } \\
100 \mathrm{PEY}^{2}\end{array}$ \\
\hline \multicolumn{4}{|c|}{ TEAEs with incidence in $\geq 15 \%$ of patients } \\
\hline Total & $1,037(98.0)$ & 17,422 & 701.9 \\
\hline IPF & $355(33.6)$ & 547 & 22.0 \\
\hline Upper RTI & $295(27.9)$ & 523 & 21.1 \\
\hline Bronchitis & $260(24.6)$ & 485 & 19.5 \\
\hline Cough & $331(31.3)$ & 436 & 17.6 \\
\hline Nausea & $305(28.8)$ & 433 & 17.4 \\
\hline Dyspnea & $327(30.9)$ & 420 & 16.9 \\
\hline Nasopharyngitis & $202(19.1)$ & 359 & 14.5 \\
\hline Diarrhea & $242(22.9)$ & 357 & 14.4 \\
\hline Fatigue & $210(19.8)$ & 251 & 10.1 \\
\hline Dizziness & $176(16.6)$ & 226 & 9.1 \\
\hline \multicolumn{4}{|c|}{ Serious TEAEs with incidence in $\geq 2 \%$ of patients } \\
\hline Total & $571(54)$ & 1,329 & 53.5 \\
\hline IPF & $230(21.7)$ & 276 & 11.1 \\
\hline Pneumonia & $90(8.5)$ & 104 & 4.2 \\
\hline Bronchitis & $32(3.0)$ & 38 & 1.5 \\
\hline Atrial fibrillation & $26(2.5)$ & 32 & 1.3 \\
\hline Acute respiratory failure & $30(2.8)$ & 30 & 1.2 \\
\hline Respiratory failure & $29(2.7)$ & 29 & 1.2 \\
\hline
\end{tabular}

IPF, idiopathic pulmonary fibrosis; PEY, patient exposure years; RTI, respiratory tract infection; TEAEs, treatment-emergent adverse events. ${ }^{1}$ Adjusted rate per $100 \mathrm{PEY}=$ (total number of events/total years of exposure) $\times 100 .{ }^{2}$ Cumulative total exposure: 2,482 PEY.

due to an AE unrelated to IPF progression (online suppl. Fig. 1B). These discontinuations resulting in study withdrawal due to AEs other than IPF most often occurred during the first year of treatment (online suppl. Fig. 1B).

ADRs occurred in 786 patients (74.3\%). The most frequent ADRs were nausea (21.6\%; 11.6 per $100 \mathrm{PEY})$, diarrhea (12.3\%; 6.9 per $100 \mathrm{PEY})$, and rash (11.6\%; 7.2 per $100 \mathrm{PEY})$, which were also observed in the phase 3 clinical trials (online suppl. Table 2). Discontinuation of pirfenidone due to an ADR occurred in 120 patients (11.3\%; 4.8 per $100 \mathrm{PEY)}$ (online suppl. Table 3). The most frequent ADRs leading to discontinuation were rash (1.1\%; 0.5 per $100 \mathrm{PEY}$ ) and nausea (1.0\%; 0.4 per $100 \mathrm{PEY})$.

Severe or life-threatening TEAEs were reported in 597 patients $(56.4 \%)$, and the most frequent ones were IPF (23.0\%), pneumonia (6.3\%), and dyspnea (5.1\%). Serious TEAEs were reported in 571 patients $(54.0 \%)$, and the most frequent serious TEAEs were IPF $(21.7 \%)$ and pneumonia (8.5\%) (Table 2). 


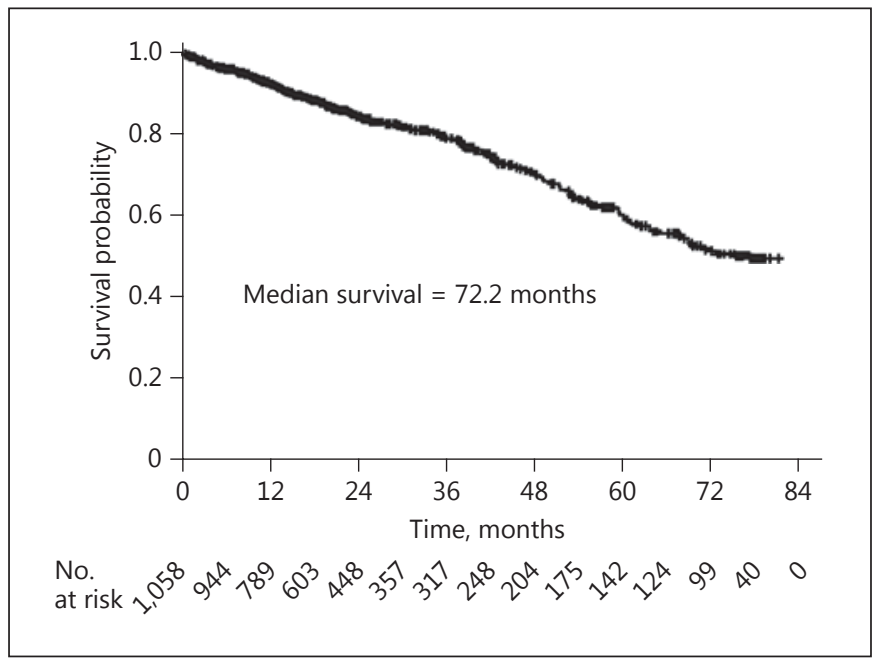

Fig. 2. On-treatment survival from the first dose of pirfenidone in RECAP (assume 1 month $=30.4375$ days).

Table 3. Summary of TEAEs resulting in pirfenidone withdrawal with incidence in $\geq 1 \%$ of patients $(n=1,058)$

\begin{tabular}{lccc}
\hline \multirow{2}{*}{ TEAEs } & $n(\%)$ & \multicolumn{2}{l}{ Adjusted rate $^{1}$} \\
\cline { 3 - 4 } & & $\begin{array}{l}\text { events, } \\
n\end{array}$ & $\begin{array}{l}\text { rate per } \\
100 \mathrm{PEY}^{2}\end{array}$ \\
\hline Total & $444(42.0)$ & 444 & 17.9 \\
IPF & $178(16.8)$ & 178 & 7.2 \\
Pneumonia & $13(1.2)$ & 13 & 0.5 \\
Respiratory failure & $13(1.2)$ & 13 & 0.5 \\
Acute respiratory failure & $12(1.1)$ & 12 & 0.5 \\
Rash & $12(1.1)$ & 12 & 0.5 \\
Nausea & $11(1.0)$ & 11 & 0.4 \\
\hline
\end{tabular}

IPF, idiopathic pulmonary fibrosis; PEY, patient exposure years; TEAEs, treatment-emergent adverse events. ${ }^{1}$ Adjusted rate per $100 \mathrm{PEY}=($ total number of events/total years of exposure $) \times$ 100. ${ }^{2}$ Cumulative total exposure: $2,482 \mathrm{PEY}$.

Death as the outcome of a TEAE was reported in 231 patients (21.8\%; 9.3 per $100 \mathrm{PEY)}$ (online suppl. Table 4). The most frequent TEAEs that resulted in death were IPF $(12.6 \%)$, respiratory failure (1.7\%), and acute respiratory failure (1.0\%). Deaths due to an ADR deemed as possibly related by investigators were reported in 13 patients (1.2\%; 0.5 per $100 \mathrm{PEY)} \mathrm{(online} \mathrm{suppl.} \mathrm{Table} \mathrm{5).}$

\section{Efficacy}

In CAPACITY 004/006 patients entering RECAP with FVC data, the annualized rate (SD) of FVC decline was
144.3 (6.0) $\mathrm{mL}$ using a linear mixed-effects model, which showed a slow decrease in FVC over the 180 -week period (online suppl. Fig. 2). The median on-treatment survival from the first dose of $2,403 \mathrm{mg} /$ day pirfenidone in RECAP was 77.2 months (Fig. 2).

\section{Discussion}

This study evaluated safety outcomes in a large cohort of patients treated with pirfenidone $2,403 \mathrm{mg}$ /day who had completed a previous phase 3 trial. RECAP provides long-term safety follow-up data for pirfenidone, with a cumulative total exposure of 2,482 PEY. At the time that patients from RECAP transitioned to commercially available pirfenidone or a posttrial access program, $40 \%$ were still receiving pirfenidone, after a median treatment duration in RECAP of 88 weeks (range $>0$ to 349 weeks).

In contrast to the phase 3 clinical trials, the frequency and adjusted rate of ADRs were lower in RECAP (74.3\%; 133.7 per 100 PEY vs. $89.2 \%$; 418.8 per $100 \mathrm{PEY})$. These results may be attributable to positive selection bias introduced by extending observations in patients with prior chronic trial exposure to pirfenidone, which is a common issue in long-term extension studies. However, the most common ADRs observed in RECAP (nausea and rash) were consistent with those seen in the phase 3 clinical trials and led to similar rates of discontinuation (1.0 vs. $1.1 \%$ and 1.1 vs. $1.4 \%$, respectively) [12]. Only 13 patients experienced an ADR that resulted in death, the most common ones being acute respiratory failure and IPF (2 each), which are indicative of the progressive nature of the disease. Overall, these data demonstrate that prolonged exposure to pirfenidone does not increase the risk of ADRs, consistent with the known safety profile of pirfenidone.

A total of $33.8 \%$ of patients discontinued RECAP due to AEs over the entire course ( $\geq 5$ years) of the study. Most discontinuations (23.0\%; online suppl. Fig. 1B) were due to AEs that were unrelated to IPF progression. These events occurred most frequently during the first year of treatment and in patients who were newly initiating pirfenidone (data not shown), suggesting that patients must be carefully monitored during this early treatment period to reduce the risk of discontinuation. Patient support programs have shown that early and careful management reduces the rate of discontinuations [18]. While the overall discontinuation rate is higher than in the shorter phase 3 trials, RECAP was a study conducted over several years, and IPF worsening did not appear to be the main driver for treatment discontinuations.
Costabel/Albera/Lancaster/Lin/Hormel/ Hulter/Noble 
The annual rate of FVC decline was $144.3 \mathrm{~mL}$ for patients who entered RECAP from CAPACITY 004/006 (no efficacy measurements were acquired in the postASCEND phase of the study), which was comparable to the 164-mL/year slope observed in the pirfenidone-treated patients in ASCEND and using a similar mixed-effects model for the calculation [2]. In addition, the annual rate of FVC decline $(\mathrm{mL})$ was similar for both prior pirfenidone-treated and prior placebo-treated patients from CAPACITY 004/006 who were treated with pirfenidone in RECAP, indicating that prior treatment did not appear to influence the annual rate of decline observed in RECAP (data not shown). The median on-treatment survival from the first dose of pirfenidone $2,403 \mathrm{mg} /$ day in RECAP was 77.2 months. These data reinforce/support the long-term efficacy of pirfenidone and suggest that the treatment benefit of pirfenidone was maintained in patients who continued receiving therapy.

These results of this study should be interpreted in the context of some limitations because of its open-label, uncontrolled design with no applicable sample size and power calculations, as well as the inherent biases in the study, including the survival bias for patients in RECAP who did not die in the previous phase 3 studies; in addition, the vital status of patients who discontinued RECAP was not captured at the end of RECAP as was done in ASCEND/ CAPACITY 004/006. Patients who did not tolerate pirfenidone were not eligible for RECAP because patients were required to have completed their previous phase 3 study and were generally compliant with study treatment. Although reasons for not rolling over into RECAP were also not collected, the majority of patients $(1,058$ of 1,089 ; 97.2\%) who completed ASCEND/CAPACITY 004/006 while on treatment enrolled into RECAP.

The long-term safety results from this study are consistent with the known safety profile of pirfenidone, with no new safety signals observed. These findings support the clinical use of pirfenidone in patients with IPF.

\section{Acknowledgments}

Safety data considerations were provided by Indiana Strombom, lead safety scientist at Genentech, Inc. Additional analyses were provided by Ben Trzaskoma and Elizabeth Morgenthien at Genentech, Inc. Support for third-party medical writing assistance for the manuscript, furnished by writer Christine Gould, PhD, CMPP, of Health Interactions, Inc., was provided by F. Hoffmann-La Roche Ltd. The sponsor oversaw the study design and data collection.

Study Investigators: USA: Allen J (The Ohio State University, Columbus, OH), Andrews C (Diagnostics Research Group, San Antonio, TX), Antin-Ozerkis D (Yale University School of Medi- cine, New Haven, CT), Bajwa A (University of Florida College of Medicine, Jacksonville, FL), Baughman R (University of Cincinnati, Cincinnati, $\mathrm{OH}$ ), Brantly $\mathrm{M}$ (University of Florida, Gainesville, FL), Butler J (Oregon Pulmonary Associates, Tualatin, OR), Chang J (Scripps Clinic/Scripps Health, Division of Chest and Critical Care Medicine, La Jolla, CA), Cordova F (Temple University Hospital, Philadelphia, PA), Covelli H (Coeur d'Alene, ID), de Andrade J (University of Alabama at Birmingham, Birmingham, AL), Dilling D (Loyola University Medical Center, Maywood, IL), Doherty D (University of Kentucky, Lexington, KY), Dushay K (Rhode Island Hospital, Providence, RI), Eaton S (Pulmonary and Critical Care of Atlanta, Atlanta, GA), Emrie P (Rocky Mountain Center for Clinical Research, Wheat Ridge, CO), Enelow R (Dartmouth-Hitchcock Medical Center, Lebanon, NH), Ettinger N (St Luke's Medical Group, Chesterfield, MO), Evans T (University of California, San Francisco - Fresno, Fresno, CA), Feldman J (Arizona Pulmonary Specialists Ltd., Phoenix, AZ), Fisher M (Emory University School of Medicine, Atlanta, GA), Flaherty K (University of Michigan Health System, Ann Arbor, MI), Foti P (Hawaii Physicians and Surgeons, Kailua, HI), Garay S (New York Pulmonary Associates, New York, NY), Gerke A (University of Iowa Hospitals and Clinics, Iowa City, IA), Ginns L (Massachusetts General Hospital, Boston, MA), Girod C (University of Texas Southwestern Medical Center, Dallas, TX), Glassberg M (University of Miami Miller School of Medicine, Miami, FL), Golden J (University of California - San Francisco, San Francisco, CA), Gotfried M (Pulmonary Associates, Phoenix, AZ), Grinnan D (Virginia Commonwealth University Health System, Richmond, VA), Haller H (Louisville Pulmonary Care, Louisville, KY), Hamblin M (University of Kansas Medical Center, Kansas City, KS), Horiuchi T (Sarasota Memorial Health Care System, Sarasota, FL), Horton M (Johns Hopkins Medical Center, Baltimore, MD), Huggins J (Medical University of South Carolina, Charleston, SC), Ilowite J (Winthrop University Hospital, Mineola, NY), Johnson L (University of Arkansas for Medical Sciences, Little Rock, AR), Kallay M (Highland Hospital, Rochester, NY), Kass D (University of Pittsburgh, Pittsburgh, PA), Kim H (University of Minnesota, Minneapolis, MN), Kinasewitz G (OU Health Sciences Center, Oklahoma City, OK), LaCamera P (Steward St Elizabeth's Medical Center, Boston, MA), Lancaster L (Vanderbilt University Medical Center, Nashville, TN), Landis J (Baystate Medical Center, Springfield, MA), Lasky J (Tulane University, New Orleans, LA), Lee A (Mayo Clinic, Jacksonville, FL), Lipchik R (Medical College of Wisconsin, Milwaukee, WI), Lorch D (PAB Clinical Research, Bradenton, FL), Lynch J (UCLA David Geffen School of Medicine, Los Angeles, CA), Mageto Y (University of Vermont, Burlington, VT), Masson J (Albany, NY), Mette S (Maine Medical Center, Portland, ME), Meyer K (University of Wisconsin Hospital and Clinics, Madison, WI), Migliore C (Barnabas Health Newark Beth Israel Medical Center, Newark, NJ), Mohabir P (Stanford University School of Medicine, Stanford, CA), Morrison L (Duke University Medical Center, Durham, NC), Morrissey B (University of California - Davis, School of Medicine and VA Northern California Health Care System, Sacramento, CA), Morrow L (Creighton University Medical Center, Omaha, NE), Nambiar A (UT Health Science Center, San Antonio, TX), Nathan S (Inova Transplant Center, Falls Church, VA), Padilla M (Icahn School of Medicine, Mount Sinai Medical Center, New York, NY), Panos R (University of Cincinnati, Cincinnati, $\mathrm{OH})$, Pantano J (Suburban Lung Associates, Elk Grove Village, IL), Parambil J (Cleveland Clinic, Cleveland, OH), Patel N (New York

Long-Term Safety in RECAP

Respiration 2017;94:408-415 
Presbyterian Hospital, Columbia University Medical Center, New York, NY), Perez R (University of Louisville School of Medicine, Louisville, KY), Rai N (Pulmonary Consultants PLLC, Tacoma, WA), Ramaswamy M (LeBaurer Healthcare, Greensboro, NC), Rose C (University of Virginia, Charlottesville, VA), Russell T (Washington University School of Medicine, St. Louis, MO), Russell D (Allergy Partners of Western North Carolina, Asheville, NC), Ryu R (Mayo Clinic, Rochester, MN), Safdar Z (Baylor College of Medicine, Houston, TX), Sanchez J (Scott \& White Memorial Hospital, Temple, TX), Schaumberg T (The Oregon Clinic, Portland, OR), Scholand MB (University of Utah, Lung Health Research Center, Salt Lake City, UT), Shen W (Southern Arizona VA Healthcare System, Tucson, AZ), Simonelli P (Geisinger Clinic/Geisinger Medical Center, Danville, PA), Sinkowitz D (UCLA David Geffen School of Medicine, Torrance, CA), Strek M (University of Chicago, Chicago, IL), Sussman R (Pulmonary and Allergy Associates, Summit, NJ), Swigris J (National Jewish Medical and Research Center, Denver, CO), Szot C (Renown Medical Group, Reno, NV), Thompson A (University of Nebraska Medical Center, Omaha, NE), Tillis W (Illinois Lung and Critical Care Institute, Peoria, IL), Tino G (Hospital of the University of Pennsylvania, Philadelphia, PA), Wencel M (Via Christi Clinic, Wichita, KS), Wesselius L (Mayo Clinic Arizona, Scottsdale, AZ), Yagan M (Midwest Pulmonary Consultants, Kansas City, MO), Yung G (University of California - San Diego, San Diego, CA), Zawadski D (Medical Consultants, Muncie, IN), Zibrak J (Beth Israel Deaconess Medical Center, Boston, MA). Australia: Corte T (Royal Prince Alfred Hospital, Camperdown, NSW), Davies H (Repatriation General Hospital, Bedford Park, SA), Glaspole I (The Alfred Hospital, Melbourne, VIC), Holmes M (Royal Adelaide Hospital, Adelaide, SA), Hopkins P (Prince Charles Hospital, Brisbane, QLD), Malouf M (St Vincent's Hospital Sydney Limited, Darlinghurst, NSW), Musk M (Royal Perth Hospital, Perth, WA), Serisier D (Mater Adult Hospital, South Brisbane, QLD), Thien F (Eastern Health and Monash University, Box Hill, VIC), Veale A (Queen Elizabeth Hospital, Woodville, SA), Veitch E (Concord Repatriation General Hospital, Concord, NSW). Belgium: Slabbynck H (AZ Middelheim, Antwerpen), Thomeer M (University Hospital Gasthuisberg, Leuven). Brazil: Alves R (Policlínica Piquet Carneiro, Universidade Estadual de Rio de Janeiro, Rio de Janeiro), Carvalho CR (Centro de Pesquisa Clínica Prof Fúlvio Pileggi, Instituto do Coração, São Paulo), Fiss E (Faculdade de Medicina do ABC, Santo André), Oliveira ME (Centro de Pesquisa de Pneumologia do Hospital Mãe de Deus, Porto Alegre), Pereira CA (Paulista School of Medicine, Federal University of São Paulo, São Paulo), Rubin A (Irmandade de Santa Casa de Misercórdia de Porto Alegre, Porto Alegre). Canada: Dhar A (Windsor, ON), Fell C (South Health Campus, University of Calgary, Calgary, AB), Homik L (Concordia Hospital, Winnipeg, MB), Khalil N (Vancouver General Hospital, Vancouver, BC), Leech JD (University of Ottawa, Ottawa, ON), Ramesh W (Edmonton, AB), Rolf JD (Kelowna, BC), Stollery D (Grey Nuns Community Hospital, Edmonton, AB), Wilcox P (St Paul's Hospital, Vancouver, BC). France: Delaval P (CHU Hôpital Pontchaillou, Rennes), Meziane L (CHU Hôpital Arnaud de Villeneuve, Montpelier), Valeyre D (Hôpital Avicenne, Bobigny), Wallaert B (Hôpital Albert Calmette, Lille). Germany: Costabel U (Ruhrlandklinik, University Hospital, University of Duisburg-Essen, Essen), Magnussen H (Pulmonary Research Institute, Grosshansdorf), Pfeifer M (Krankenhaus Donaustauf, Donaustauf), Worth H (Klinikum Fürth, Fürth). Israel: Breuer R (Institute of Pulmonology, Hadassah Hebrew Uni- versity Medical Center, Jerusalem), Kramer M (Pulmonary Institute, Rabin Medical Center, Petah Tikva), Schwarz Y (Tel Aviv Sourasky Medical Center, Tel Aviv), Segel M (Sheba Medical Center, Sackler Faculty of Medicine, Tel Aviv University, Tel Aviv), Yigla M (Ramban Health Care Campus, Haifa). Italy: Agostini C (Università degli Studi di Padova, Padova), Albera C (Clinica Malattie dell'Apparato Respiratorio, University of Turin, Turin), Bertorelli G (University of Parma, Parma), Confalonieri M (Azienda Ospedaliera Universitaria, Trieste), Harari S (Ospedale San Giuseppe, Milano), Poletti V (Azienda Sanitaria di Forli, Forli), Richeldi L (Azienda Policlinico di Modena, Modena), Rottoli P (Azienda Ospedaliera Universitaria Policlinico Le Scotte, Siena), Saltini C (Azienda Ospedaliera Universitaria Policlinico Tor Vergata, Rome). Mexico: Chavarria Martinez U (Centro de Prevención y Rehabilitación de Enfermedades Pulmonares Crónicas, Hospital Universitario “Dr José Eleuterio González," Monterrey), Diaz Castañón JJ (Hospital Angel Leaño, Zapopan), Perea Sanchez RA (Hospital Central Universitario de Chihuahua, Chihuahua), Selman-Lama ME (Instituto Nacional de Enfermedades Repiratorias Ismael Cosío Villegas, Tlalpan). New Zealand: Beckert L (University of Otago, Christchurch, Christchurch), Wilsher M (Greenlane Clinical Center, Auckland). Peru: Castro Bernardini SU (Neumocare, Clínica San Borja, Lima), Guerreros Benavides AG (Clínica Internacional Sede Centro, Lima), Iberico Barrera CA (Investigaciones Médicas en Salud, Lima), Matsuno Fuchigami AG (Unidad de Investigación de Enfermedades Respiratorias, Clínica San Pablo, Lima), Piñeiro Garca Calderón A (Clínica Ricardo Palma, Lima), Pun Leon LE (Clínica Ricardo Palma, Lima), Salazar Oré DJ (Hospital Nacional Cayetano Heredia, Lima), Torres Sales JW (Clínica Internacional Sede San Borja, Lima). Poland: Kus J (Instytut Gruzlicy I Chorob Pluc, Warsaw), Ziora D (Samodzielny Publiczny Szpital, Zabrze). Singapore: Low SY (Singapore General Hospital). Spain: Ancochea Bermudez J (Hospital Universitario de la Princesa, Madrid), Batista JJ (Hospital Universitario Nuestra Señora de la Candelaria, Santa Cruz de Tenerife), Morell Brotad F (Hospital Vall d'Hebron, Barcelona), Xaubet Mir A (Universitat de Barcelona, Barcelona). UK: Burge S (Birmingham Heartlands Hospital, Birmingham), Leonard CA (Whythenshawe Hospital, Manchester), Wells A (Royal Brompton Hospital, London).

\section{Financial Disclosure and Conflicts of Interest}

U. Costabel was an advisor to InterMune (wholly owned Roche subsidiary since 2014), Boehringer Ingelheim, Bayer, Roche, and Gilead on IPF trials and has received lecture fees from InterMune, Bayer, and Boehringer Ingelheim. C. Albera was a member of the steering committee at InterMune as well as a consultant and investigator in the clinical trials. L.H. Lancaster was a consultant for InterMune and Boehringer Ingelheim. H.N. Hulter was a consultant for Genentech, Inc. P. Hormel and C.-Y. Lin are employees of Genentech, Inc. P.W. Noble was a consultant for InterMune, Boehringer Ingelheim, Genentech, Inc., GlaxoSmithKline, and Moerae Matrix.

\section{Funding Sources}

This study was funded by F. Hoffmann-La Roche Ltd./Genentech, Inc.
414

Respiration 2017;94:408-415

DOI: $10.1159 / 000479976$
Costabel/Albera/Lancaster/Lin/Hormel/ Hulter/Noble 


\section{Author Contributions}

U. Costabel had full access to all of the data in the study and takes responsibility for the integrity of the data and the accuracy of the data analysis. H.N. Hulter, P. Hormel, and C.-Y. Lin (Genen- tech, Inc.) conducted and are responsible for the data analysis. All authors had access to the data and interpreted them as well as contributed to the preparation, review, and approval of the manuscript. U. Costabel had the final full responsibility for the decision to submit the manuscript for publication.

\section{References}

1 Raghu G, Rochwerg B, Zhang Y, Garcia CA, Azuma A, Behr J, Brozek JL, Collard HR, Cunningham W, Homma S, Johkoh T, Martinez FJ, Myers J, Protzko SL, Richeldi L, Rind D, Selman M, Theodore A, Wells AU, Hoogsteden H, Schunemann HJ; American Thoracic Society; European Respiratory Society; Japanese Respiratory Society; Latin American Thoracic Association: An Official ATS/ERS/ JRS/ALAT clinical practice guideline: treatment of idiopathic pulmonary fibrosis. An update of the 2011 clinical practice guideline. Am J Respir Crit Care Med 2015;192:e3-e19.

2 King TE Jr, Bradford WZ, Castro-Bernardini S, Fagan EA, Glaspole I, Glassberg MK, Gorina E, Hopkins PM, Kardatzke D, Lancaster L, Lederer DJ, Nathan SD, Pereira CA, Sahn SA, Sussman R, Swigris JJ, Noble PW; ASCEND Study Group: A phase 3 trial of pirfenidone in patients with idiopathic pulmonary fibrosis. N Engl J Med 2014;370:2083-2092.

3 Noble PW, Albera C, Bradford WZ, Costabel U, Glassberg MK, Kardatzke D, King TE Jr, Lancaster L, Sahn SA, Szwarcberg J, Valeyre D, du Bois RM; CAPACITY Study Group: Pirfenidone in patients with idiopathic pulmonary fibrosis (CAPACITY): two randomised trials. Lancet 2011;377:1760-1769.

4 Taniguchi H, Ebina M, Kondoh Y, Ogura T, Azuma A, Suga M, Taguchi Y, Takahashi H, Nakata K, Sato A, Takeuchi M, Raghu G, Kudoh S, Nukiwa T; Pirfenidone Clinical Study Group in Japan: Pirfenidone in idiopathic pulmonary fibrosis. Eur Respir J 2010;35: 821-829.

5 Loeh B, Drakopanagiotakis F, Bandelli GP, von der Beck D, Tello S, Cordani E, Rizza E, Barrocu L, Markart P, Seeger W, Guenther A, Albera C: Intraindividual response to treatment with pirfenidone in idiopathic pulmonary fibrosis. Am J Respir Crit Care Med 2015;191:110-113.
6 Chaudhuri N, Duck A, Frank R, Holme J, Leonard C: Real world experiences: pirfenidone is well tolerated in patients with idiopathic pulmonary fibrosis. Respir Med 2014; 108:224-226.

7 Oltmanns U, Kahn N, Palmowski K, Trager A, Wenz H, Heussel CP, Schnabel PA, Puderbach M, Wiebel M, Ehlers-Tenenbaum S, Warth A, Herth FJ, Kreuter M: Pirfenidone in idiopathic pulmonary fibrosis: real-life experience from a German tertiary referral center for interstitial lung diseases. Respiration 2014;88:199-207.

8 Wijsenbeek MS, Grutters JC, Wuyts WA: Early experience of pirfenidone in daily clinical practice in Belgium and the Netherlands: a retrospective cohort analysis. Adv Ther 2015; 32:691-704.

9 du Bois RM, Weycker D, Albera C, Bradford WZ, Costabel U, Kartashov A, Lancaster L, Noble PW, Raghu G, Sahn SA, Szwarcberg J, Thomeer M, Valeyre D, King TE Jr: Ascertainment of individual risk of mortality for patients with idiopathic pulmonary fibrosis. Am J Respir Crit Care Med 2011;184:459466.

10 Karimi-Shah BA, Chowdhury BA: Forced vital capacity in idiopathic pulmonary fibrosis - FDA review of pirfenidone and nintedanib. N Engl J Med 2015;372:1189-1191.

11 Noble PW, Albera C, Bradford WZ, Costabel U, du Bois RM, Fagan EA, Fishman RS, Glaspole I, Glassberg MK, Lancaster L, Lederer DJ, Leff JA, Nathan SD, Pereira CA, Swigris JJ, Valeyre D, King TE Jr: Pirfenidone for idiopathic pulmonary fibrosis: analysis of pooled data from three multinational phase 3 trials. Eur Respir J 2016;47:243-253.
12 Lancaster L, Albera C, Bradford WZ, Costabel U, du Bois RM, Fagan EA, Fishman RS, Glaspole I, Glassberg MK, King TE Jr, Lederer DJ, Lin Z, Nathan SD, Pereira CA, Swigris JJ, Valeyre D, Noble PW: Safety of pirfenidone in patients with idiopathic pulmonary fibrosis: integrated analysis of cumulative data from 5 clinical trials. BMJ Open Respir Res 2016;3: e000105.

13 Valeyre D, Albera C, Bradford WZ, Costabel U, King TE Jr, Leff JA, Noble PW, Sahn SA, du Bois RM: Comprehensive assessment of the long-term safety of pirfenidone in patients with idiopathic pulmonary fibrosis. Respirology 2014;19:740-747.

14 Cottin V, Maher T: Long-term clinical and real-world experience with pirfenidone in the treatment of idiopathic pulmonary fibrosis. Eur Respir Rev 2015;24:58-64.

15 Costabel U, Bendstrup E, Cottin V, Dewint P, Egan JJ, Ferguson J, Groves R, Hellstrom PM, Kreuter M, Maher TM, Molina-Molina M, Nordlind K, Sarafidis A, Vancheri C: Pirfenidone in idiopathic pulmonary fibrosis: expert panel discussion on the management of drugrelated adverse events. Adv Ther 2014;31: 375-391.

16 Costabel U, Albera C, Bradford WZ, Hormel P, King TE Jr, Noble PW, Sahn SA, Valeyre D, du Bois RM: Analysis of lung function and survival in RECAP: an open-label extension study of pirfenidone in patients with idiopathic pulmonary fibrosis. Sarcoidosis Vasc Diffuse Lung Dis 2014;31:198-205.

17 Esbriet (pirfenidone) capsules, for oral use (package insert). South San Francisco, Genentech, January 2017.

18 Duck A, Pigram L, Errhalt P, Ahmed D, Chaudhuri N: IPF Care: a support program for patients with idiopathic pulmonary fibrosis treated with pirfenidone in Europe. Adv Ther 2015;32:87-107. 